\title{
Study on the Characteristics of Formaldehyde Pollution in Typical Teaching Machine Room
}

\author{
Pengpeng Yang, Mianwu Meng*, Dingding Gao, Zhihao Lin, Hua Ding, Mengke Tian, Chunqiang Chen, Zhenming Zhou, \\ Siyu Huang, Caiyan Kang
}

College of Environment and Resources, Guangxi Normal University, Guilin, Guangxi 541004, China

\begin{abstract}
This study focused on measuring the pollution characteristics, the monthly and seasonal variation rule of formaldehyde in the teaching machine room of Guangxi Normal University from March 2016 to February 2018, and the correlation between formaldehyde concentration and temperature or humidity were also analyzed. The results indicated that seasonal and monthly variation rule of formaldehyde changed with temperature and humidity in the teaching machine room. The concentration of formaldehyde was higher in summer and autumn, while was lower in winter and spring. Further analysis indicated that there was a strongly positive correlation $\left(\mathrm{R}^{2}>0.87, \mathrm{R}^{2}>0.85, \mathrm{R}^{2}>0.81, \mathrm{p}<0.01\right)$ between formaldehyde concentration and temperature, relative humidity or absolute humidity. It concluded that the formaldehyde concentration increased with the increase in the temperature and humidity. The maximum concentrations of formaldehyde in sitting breathing area and standing breathing area were $0.442 \mathrm{mg} / \mathrm{m}^{3}$, $0.445 \mathrm{mg} / \mathrm{m}^{3}$ and $0.184 \mathrm{mg} / \mathrm{m}^{3}, 0.213 \mathrm{mg} / \mathrm{m}^{3}$ in July 2016,2017 , respectively. After eleven years, the formaldehyde in the teaching machine room was still seriously exceeded the standard $(0.1 \mathrm{~mol} / \mathrm{L})$, and decreased the temperature or humidity could effective alleviate the level of indoor formaldehyde concentration.
\end{abstract}

\section{Introduction}

With the improvement of economic level and life style, people's concept of production and life is changing constantly [1], and in order to make the indoor environment more comfortable and beautiful, the upsurge of decoration continues to rise [2]. In recent years, the problem of indoor air pollution has become more and more seriously, which has critically endangered human safety that a lot of research has also been carried out at domestic and abroad [3, 4]. Formaldehyde is one of the causes of human disease [5], the weekly prevalence of rhinitis or eye, throat, skin symptoms were $18.8 \%, 11.6 \%$, $15.6 \%$ and $11.1 \%$, respectively [6]. The exposure of indoor formaldehyde may increase the risk of common cold in children [7, 8]. The release of pollutants (VOCs and formaldehyde) from the inner wall covered by wallpaper increased the prevalence of atopic dermatitis [9]. Formaldehyde is a common indoor air pollutant, which has obvious effect on human health [10].

Investigation 32 kinds of indoor pollutants in 18 schools indicated that formaldehyde was the main pollutant in the school [11], and the average formaldehyde concentration significantly exceeded the standard in a primary school of eastern Serbia towns [12]. The concentration of formaldehyde or acetaldehyde, acetone, toluene, hexanal in Beijing residential room was $55.1 \mu \mathrm{g} / \mathrm{m}^{3}$ or $18.7 \mu \mathrm{g} / \mathrm{m}^{3}, \quad 14.8 \mu \mathrm{g} / \mathrm{m}^{3}, \quad 14.1 \mu \mathrm{g} / \mathrm{m}^{3}$, $13.8 \mu \mathrm{g} / \mathrm{m}^{3}$, respectively [13]. The concentrations of formaldehyde and TVOC in $\mathrm{Xi}^{\prime}$ an underground shopping malls ranged from $0.05 \mathrm{mg} / \mathrm{m}^{3} \sim 0.2605 \mathrm{mg} / \mathrm{m}^{3}$ and $0.3405 \mathrm{mg} / \mathrm{m}^{3} \sim 3.5605 \mathrm{mg} / \mathrm{m}^{3}$ [14], and the concentrations of TVOC $\left(1.15 \mathrm{mg} / \mathrm{m}^{3}\right)$ and formaldehyde $\left(2.3 \mathrm{mg} / \mathrm{m}^{3}\right)$ exceeded the national standard in the newly renovated shopping malls [15]. In the underground platform of subway station, the concentrations of TVOCs or PM10, PM2.5 were higher than the regulated standards stipulated by Taiwan's Environmental Protection Administration [16]. Analysis found that indoor formaldehyde concentration of $30.12 \mu \mathrm{g} / \mathrm{m}^{3}$ was slightly higher than that of outdoor $27.80 \mu \mathrm{g} / \mathrm{m}^{3}$ [17], and the concentration of formaldehyde in indoor were $0.21 \mathrm{mg} / \mathrm{m}^{3}, 0.11 \mathrm{mg} / \mathrm{m}^{3}$, $0.04 \mathrm{mg} / \mathrm{m}^{3}$ after 3 months, 6 months, 12 months of decoration [18] which decreased with the passage of time $[19,20]$.

It exited positively correlated between indoor formaldehyde concentration and temperature or humidity $[21,22]$. The average indoor formaldehyde concentration in North and South of China were $56 \mu \mathrm{g} / \mathrm{m}^{3}$ and $40 \mu \mathrm{g} / \mathrm{m}^{3}$ [23], and the indoor concentration of formaldehyde in Beijing of summer was 1.63 times of winter [24]. Studied found that the temperature and humidity have a great influence on the emission of formaldehyde from wood-based panels [25], humidity promoted the formaldehyde emission of medium density fiberboard [26]. In the newly house, furniture and building materials were the main source of formaldehyde [5], which contributed $45 \%$ and $43 \%$ to indoor formaldehyde

\footnotetext{
*Corresponding author: 897405894@qq.com
} 
concentration [27], and the release of formaldehyde from indoor wood materials was decrease with the passage of time [28]. Differences in building structure may affect the release of indoors formaldehyde [29], and VOC contaminants vary in two different types of wards [30]. Human activities will affect the release of pollutants that also increase the indoor concentration of formaldehyde $[31,32]$. It can be seen that the indoor formaldehyde release were affected by indoor temperature or humidity, human activities, which the furniture and building materials were the main source. So far, numerous indoor air pollution studies in China have focused on the concentration of formaldehyde in public places, but little is known about the effect of indoor factors on indoor formaldehyde concentration. Considering these facts, a comprehensive study about the rule and external factors that formaldehyde emission in the teaching machine room seemed worthy of effort.

The main objective of this study was to study the monthly and seasonal variation rule of formaldehyde concentration in the teaching machine room, and the correlation between formaldehyde concentration and indoor temperature or absolute humidity, relative humidity were also analyzed.

\section{Materials and Methods}

\subsection{Sampling Sites}

In this study, the sampling point set in the teaching machine room of Guangxi Normal University. The teaching machine room $(17600 \mathrm{~mm} \times 9670 \mathrm{~mm} \times 3900 \mathrm{~mm})$ was asemi-enclosed environment and built in March 2006, with a computer desk made of veneer particleboard. According to the HJ/T167-2004 "Technical Specification for Indoor Ambient Air Quality Monitoring" [33], the diagonal layout method was used for set sampling points in the teaching machine room. A total of 9 sampling points set in the teaching machine room, which 5 sampling points distributed on each diagonal line. The sampling points were located over $0.5 \mathrm{~m}$ away from the ventilation and exterior wall, and the formaldehyde of sitting breathing area (1m from the floor) or standing breathing area $(1.5 \mathrm{~m}$ from the floor) were monitored. The sampling point distribution is shown in Figure 1. In order to ensure the reliability of the experimental data, the monitoring time of teaching machine room were13:00pm-14:00pm every three days from March 2016 to February 2018, and repeat three times for each sample.

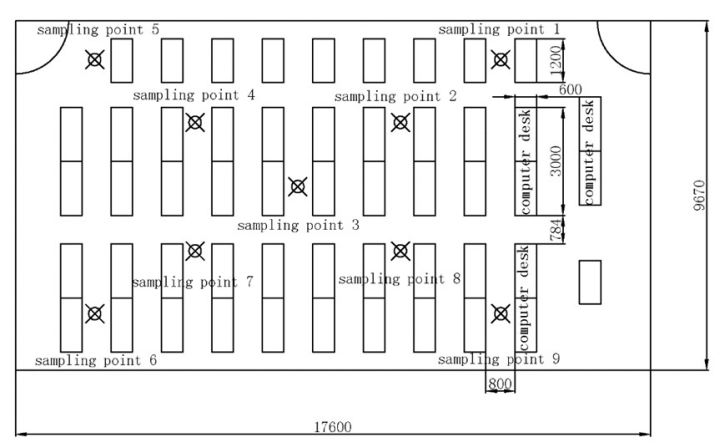

Fig. 1. Distribution map of sampling point in teaching machine room

\subsection{Experiments and Methods}

In this study, the bubble absorption tube was as the research object, and the sampled digital constant current sampler (HL- II / IV , Shanghai Buqing Technology Development Co, Ltd.) was used to study the formaldehyde in the teaching machine room. Before and after sampling, the sampling series flow rate was accurately calibrated with a soap flow meter (ZR-5310, Qingdao Chengxintong Instrument Co, Ltd.), with a sampling range of $0-1 \mathrm{~L} / \mathrm{min}$ and accuracy of $\pm 2 \%$. The Phenol reagent spectrophotometry (GB/T18204.26-2000) [34] was a standard method for the determination of formaldehyde concentration, and correlation analytical methods for indoor formaldehyde can also be found in elsewhere [35]. In this paper, the concentration of formaldehyde was determined by phenol reagent spectrophotometer (China Shanghai Optical Instrument Factory Co, Ltd. 72N), which absorption peak was at $630 \mathrm{~nm}$. The temperature and humidity meter (TH108, Shenzhen Hongmao Instrument and Meter Factory) continuously record the values of indoor temperature and humidity. The indoor temperature measurement range was $-10^{\circ} \mathrm{C}-50^{\circ} \mathrm{C}$ which the accuracy was $\pm 1{ }^{\circ} \mathrm{C}$, and the indoor relative humidity was measured from $10 \%$ to $99 \%$ with an accuracy of $2 \%$.

\subsection{Statistical Analyses and Evaluation Standard}

In this paper, statistical analysis of measurement data was performed on the measured data using Microsoft Excel (version 2010), Origin (version 8.5). The "Indoor Air Quality Standard (GB/T1883-2002)" [36] and the formaldehyde limit standard $\left(0.1 \mathrm{mg} / \mathrm{m}^{3}\right)$ were used as the evaluation criteria for indoor formaldehyde concentration to determine whether formaldehyde exceeded the standard in the teaching machine room.

\subsection{Quality Assurance and Quality Control}

In order to ensure the reliability and accuracy of the monitoring results, the analysis and determination of formaldehyde was strictly in accordance with the standard method (GB/T18204. 26-2000) [34]. Before sampling, the teaching machine room was sealed for $12 \mathrm{~h}$. 
After the sampling was completed, the sample was placed in a plastic bag and measured within $24 \mathrm{~h}$ at room temperature. A $1.0 \mu \mathrm{g} / \mathrm{ml}$ aqueous formaldehyde solution was used as the calibration standard solution prior to analysis of the absorbed sample, and a formaldehyde concentration calibration curve was established using eight standard formaldehyde concentrations. Calibration standards include routine operational maintenance and standard sample calibration, and were run and tested daily using the same analytical procedure to ensure sample stability. To ensure the validity of the results, walking disturbances should be avoided during monitoring process and each sample should be analyzed in parallel.

\section{Results and Discussion}

\subsection{Seasonal Variation Rule of Formaldehyde Concentration}

In order to study the seasonal variation rule of formaldehyde in the teaching machine room of Guangxi Normal University from March 2016 to February 2018. We measured and analyzed the monitoring results of formaldehyde in sitting breathing area and standing breathing area of the teaching machine room. The seasonal variation rule of formaldehyde in different respiratory areas of the teaching machine room is shown in Figure 2.
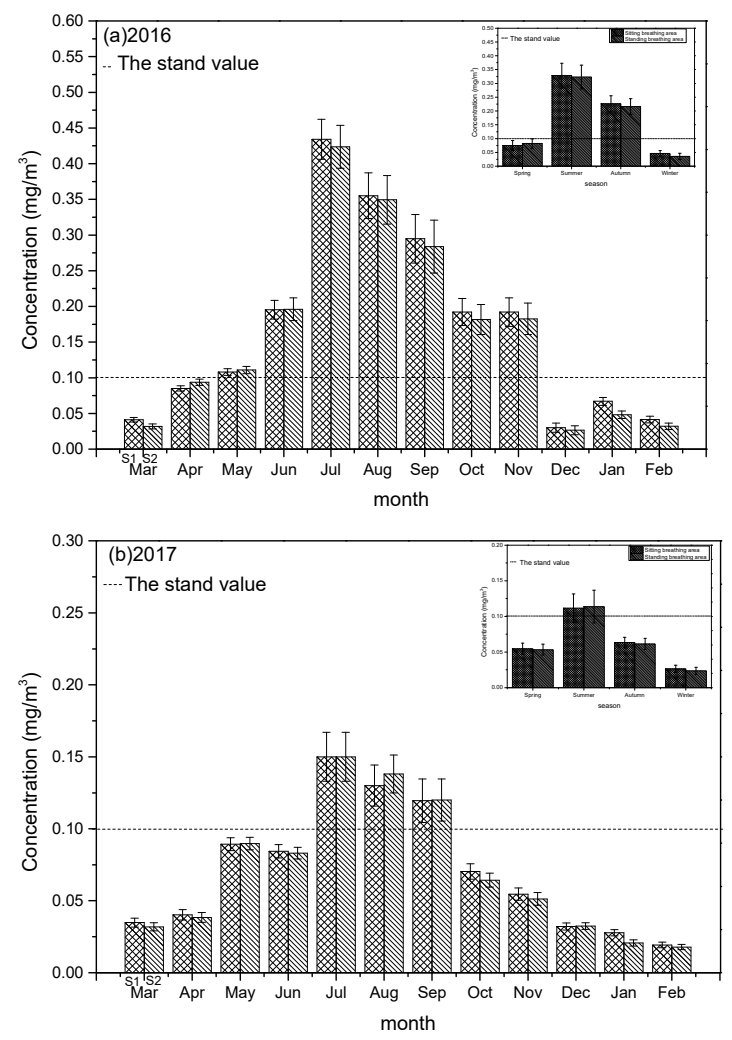

Fig. 2. Seasonal variation rule of formaldehyde concentration: (a) 2016.3-2017.2, (b) 2017.3-2018.2

The concentration of formaldehyde in the teaching machine room within two years is shown in Figure 2.
There are seven months concentration of formaldehyde exceeded the standard $\left(0.1 \mathrm{mg} / \mathrm{m}^{3}\right)$ in the sitting area (S1) and standing breathing area (S2) from March 2016 to February 2017. The over-standard rate of formaldehyde measured in the sitting breathing area and standing breathing area was $58.33 \%$. The maximum concentrations of formaldehyde in sitting breathing area and standing breathing area were $0.432 \mathrm{mg} / \mathrm{m}^{3}$, $0.435 \mathrm{mg} / \mathrm{m}^{3}$ in July of 2016. The formaldehyde concentrations in summer and autumn exceeded the standard values, while it did not exceed the standard in spring and winter. The formaldehyde concentration in the sitting breathing area was slightly higher than that in the standing breathing area, except for April, May and June (Figure 2 (a)). There are three months concentration of formaldehyde exceeded the limit value $\left(0.1 \mathrm{mg} / \mathrm{m}^{3}\right)$ in the sitting area (S1) and standing breathing area (S2) from March 2017 to February 2018. The over-standard rate of formaldehyde measured in the sitting breathing area and standing breathing area was $25 \%$, and only summer exceeded the standard value. The concentration of formaldehyde in the sitting and standing breathing areas reached a maximum of $0.184 \mathrm{mg} / \mathrm{m}^{3}, 0.213 \mathrm{mg} / \mathrm{m}^{3}$ in July 2017. During the monitoring period, except for August and September, the formaldehyde concentration in the sitting breathing area was slightly higher than that in the standing breathing area (Figure 2 (b)).

It can also be seen from Figure 2, in the two-year monitoring period, the formaldehyde concentration of each month in the teaching machine room from March 2017 to February 2018 was lower than the corresponding month of formaldehyde concentration from March 2016 to February 2017. With the change of time, the formaldehyde concentration showed a change rule of increasing first and then decreasing (Figure 2 (a) and Figure 2 (b)). The change of formaldehyde in the sitting breathing area and standing breathing area of the teaching machine room was small. The seasonal variation rule of formaldehyde concentration in the sitting breathing area and standing breathing area was basically the same, while the formaldehyde concentration changes greatly in the different seasons. Formaldehyde is mainly derived from plywood such as tables and chair [37], and outdoor formaldehyde is also a cause of the increase of formaldehyde concentration in the room [38].

\subsection{Monthly Variation Rule of Formaldehyde Concentration}

According to the above analysis results, we select the typical months as monitoring point in the sitting breathing area and standing breathing area of the teaching machine room from March 2016 to February 2018. In order to study the monthly variation rule of formaldehyde in the teaching machine room, we further analyzed the concentration characteristics of formaldehyde. Figure 3 and Figure 4 show the monthly variation rule of formaldehyde in different respiratory areas of the teaching machine room. 

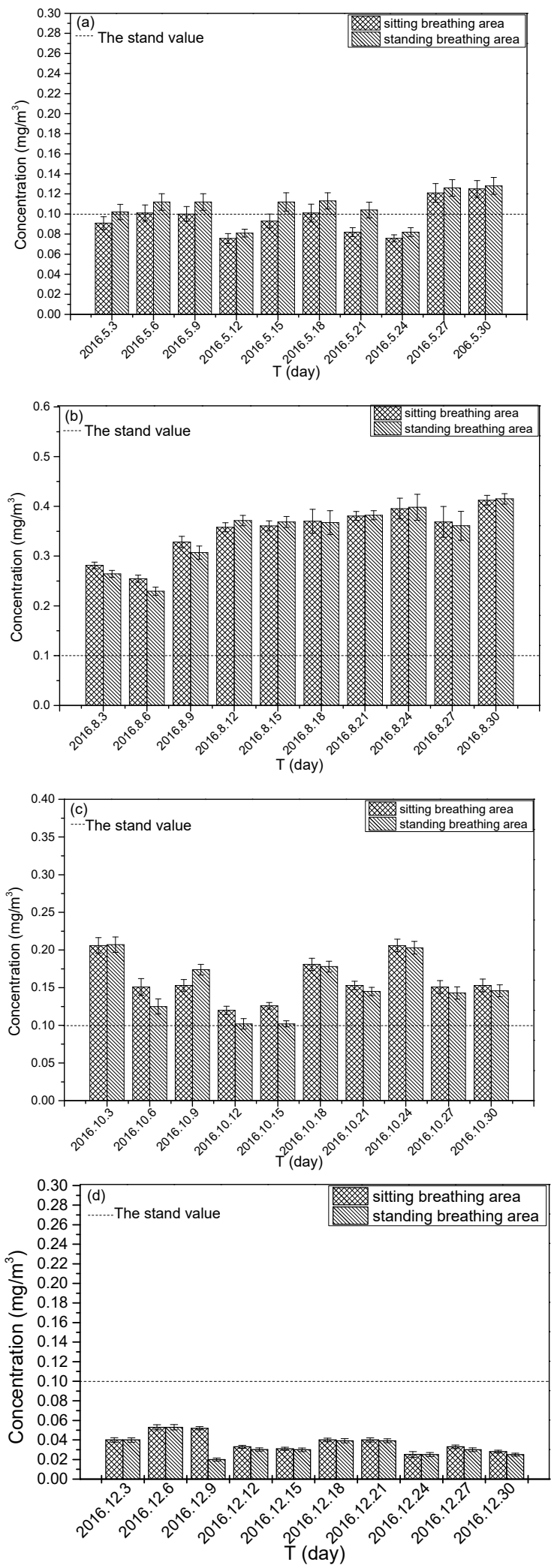

Fig. 3. Monthly variation rule of formaldehyde concentration: (a) 2016.5, (b) 2016.8, (c) 2016.10, (d) 2016.12
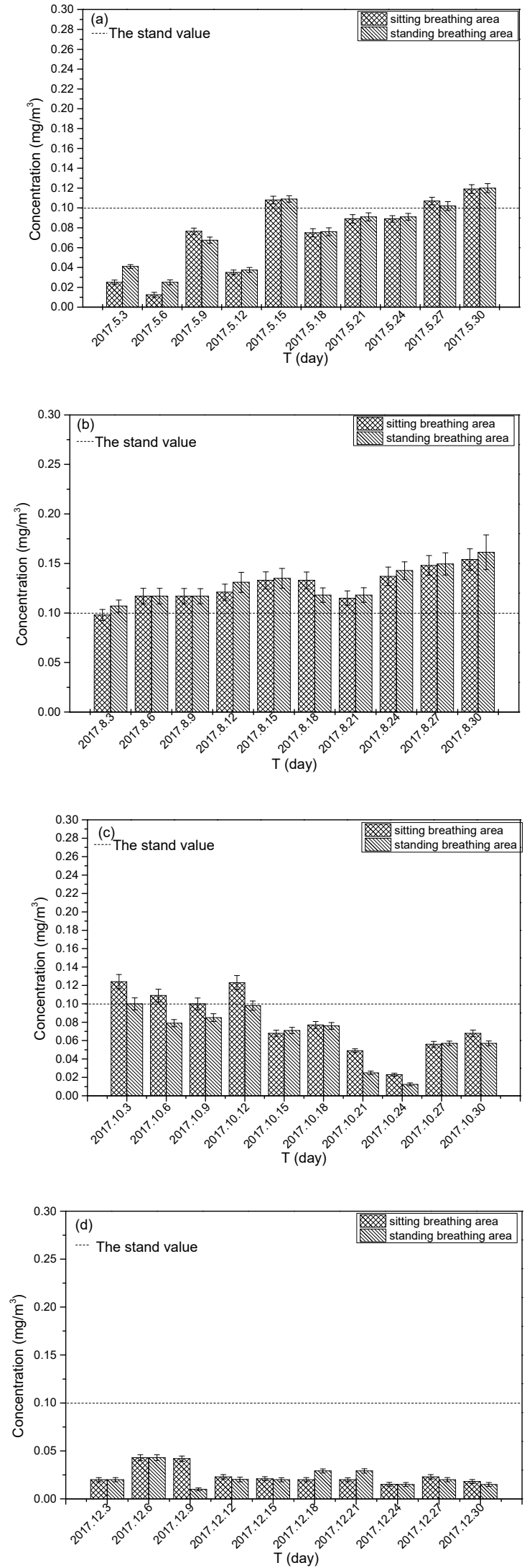

Fig. 4. Monthly variation rule of formaldehyde concentration: (a) 2017.5 , (b) 2017.8 , (c) 2017.10 , (d) 2017.12

The variation in formaldehyde concentration in the teaching machine room during the monitoring period of 2016.3-2017.2 is shown in Figure3. The formaldehyde 
concentration in the standing breathing area was slightly higher than the sitting breathing area, and the over-standard rate of formaldehyde measured in the standing breathing area was $80 \%$. The maximum and minimum concentrations of formaldehyde were $0.125 \mathrm{mg} / \mathrm{m}^{3}, \quad 0.0756 \mathrm{mg} / \mathrm{m}^{3} \quad$ and $\quad 0.128 \mathrm{mg} / \mathrm{m}^{3}$, $0.081 \mathrm{mg} / \mathrm{m}^{3}$ in the sitting breathing area and standing breathing area, respectively (Figure 3 (a)). The maximum and minimum concentrations of formaldehyde were $0.412 \mathrm{mg} / \mathrm{m}^{3}, 0.254 \mathrm{mg} / \mathrm{m}^{3}$ and $0.415 \mathrm{mg} / \mathrm{m}^{3}, 0.229 \mathrm{mg} / \mathrm{m}^{3}$ in the sitting breathing area and standing breathing area, respectively. All concentration of formaldehyde measured in the sitting breathing area and standing breathing area exceeded the standard limit (Figure 3 (b)). The formaldehyde concentration in the standing breathing area was slightly lower than the sitting breathing area, except for 3th and 9th days. The over-standard rate of formaldehyde measured in the sitting breathing area and standing breathing area was $100 \%$ (Figure 3 (c)). The maximum and minimum concentrations of formaldehyde were $0.053 \mathrm{mg} / \mathrm{m}^{3}$, $0.0252 \mathrm{mg} / \mathrm{m}^{3}$ and $0.053 \mathrm{mg} / \mathrm{m}^{3}, 0.02 \mathrm{mg} / \mathrm{m}^{3}$ in the sitting breathing area and standing breathing area, respectively. All concentration of formaldehyde measured in the sitting breathing area and standing breathing area were below the standard value $\left(0.1 \mathrm{mg} / \mathrm{m}^{3}\right)$ (Figure $3(\mathrm{~d})$ ).

Figure 4 shows the change in formaldehyde concentration in the teaching room from March 2017 to February 2018. The maximum and minimum concentrations of formaldehyde reached $0.119 \mathrm{mg} / \mathrm{m}^{3}$, $0.0125 \mathrm{mg} / \mathrm{m}^{3}$ and $0.12 \mathrm{mg} / \mathrm{m}^{3}, 0.025 \mathrm{mg} / \mathrm{m}^{3}$ in the sitting breathing area and standing breathing area, respectively. The over-standard rate of formaldehyde measured in the sitting breathing area and standing breathing area was 30\% (Figure 4 (a)). All concentration of formaldehyde measured in the sitting breathing area and standing breathing area were above the standard value. The maximum in formaldehyde concentration in the sitting breathing area and standing breathing area were $0.154 \mathrm{mg} / \mathrm{m}^{3}$ and $0.161 \mathrm{mg} / \mathrm{m}^{3}$ (Figure 4 (b)). The concentration of formaldehyde in the sitting breathing area and standing breathing area gradually decreased except for the 27 th and 30th days. The formaldehyde concentration in the sitting breathing area and standing breathing area reached a maximum of $0.124 \mathrm{mg} / \mathrm{m}^{3}$ and $0.1 \mathrm{mg} / \mathrm{m}^{3}$ on the third day (Figure 4 (c)). The formaldehyde concentrations in the sitting breathing area and standing breathing area were below the standard limit (Figure $4(\mathrm{~d})$ ).

Comparing Figure 3 and Figure 4, it can be found that the daily concentration of formaldehyde in the sitting breathing area and standing breathing area from March 2016 to February 2017 was slightly higher than that of March 2017 to February 2018. There is little difference in the daily variation of formaldehyde concentration within one month. In general, the difference in formaldehyde concentration between month and month is mainly due to temperature [39].

\subsection{Effect of temperature and humidity on Formaldehyde Concentration}

In order to study the correlation between formaldehyde concentration and temperature or humidity in the teaching machine room, we systematically analyzed the relationship between formaldehyde concentration and temperature or humidity in the experimental data of three groups in the teaching machine room, as shown in Figure 5. And the relationship matrix between formaldehyde and temperature or humidity is shown Table 1.
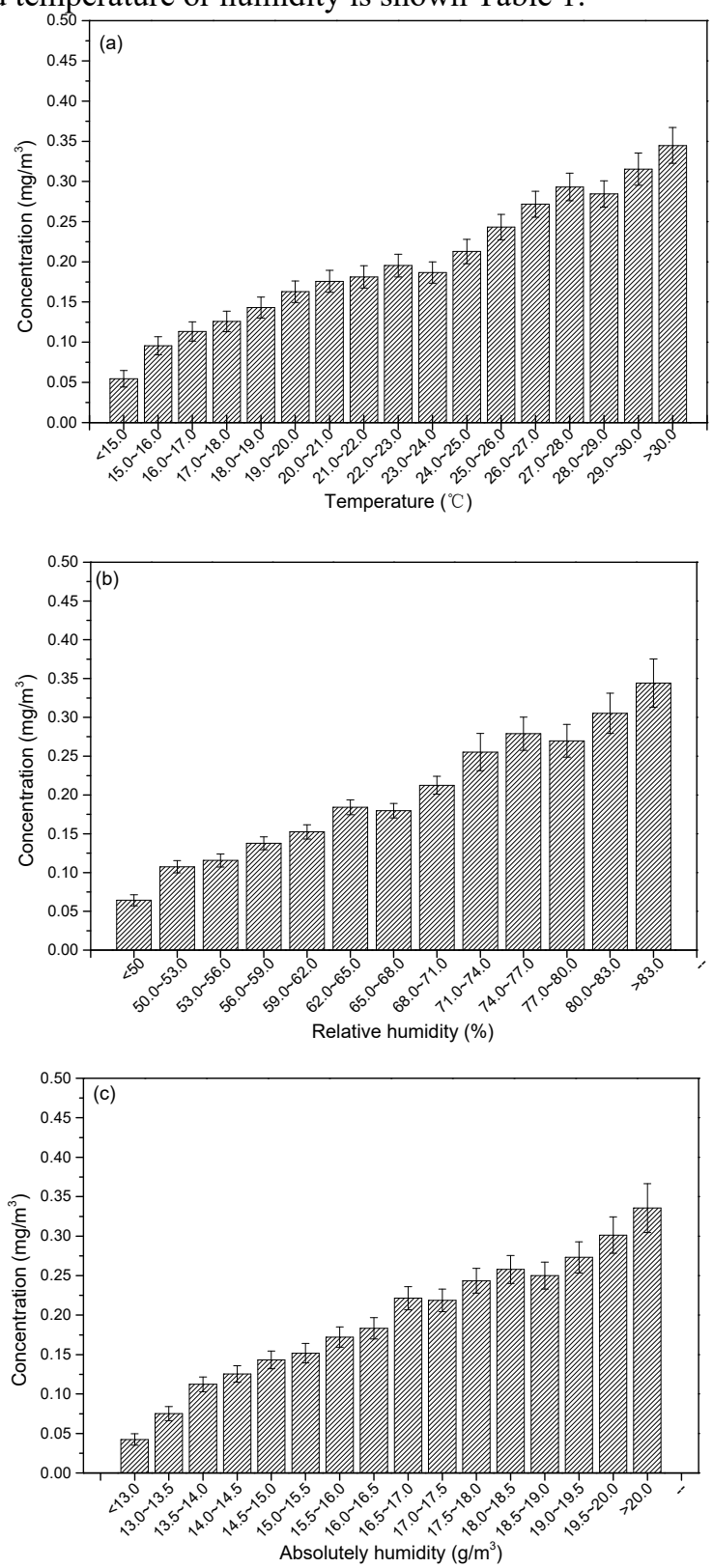

Fig. 5. The correlation between formaldehyde concentration and indoor temperature or relative humidity, absolute humidity: (a) temperature, (b) relative humidity, (c) absolutely humidity

Table 1. The matrix between formaldehyde concentration and temperature or humidity in the teaching machine room

\begin{tabular}{|c|c|cc|}
\hline Sit & \multicolumn{3}{|c|}{ Teaching machine room } \\
\hline Temperature & \multirow{3}{*}{ Pearson $\mathrm{R}^{2}$} & $0.87^{* *}$ & $(\mathrm{n}=720)$ \\
\cline { 1 - 1 } & & $0.85^{* *}$ & $(\mathrm{n}=720)$ \\
\hline Relative humidity & $0.81^{* *}$ & $(\mathrm{n}=720)$ \\
\hline Absolute humidity & & & \\
\hline
\end{tabular}

*Significance level at 0.01(two-tailed) 
The effect of temperature and humidity on formaldehyde concentration is shown in Figure 5. It can be concluded that the release of formaldehyde was significantly correlated $\left(\mathrm{R}^{2}>0.87, \mathrm{R}^{2}>0.85, \quad \mathrm{R}^{2}>0.81\right.$, $\mathrm{p}<0.01$ ) with temperature, relative humidity or absolute humidity (Table 1). The order of influence of environmental factors on formaldehyde concentration was temperature $>$ relative humidity $>$ absolute humidity. The indoor formaldehyde concentration gradually increase with the increase of temperature, relative humidity or absolute humidity (Figure 5 (a), (b), (c)), which further indicted that temperature and humidity were the main factors affecting the release of formaldehyde $[35,40]$. The similar results were obtained in New Decorated Residential Buildings [21, 22].

Guangxi is a high-temperature and high-humidity climate. The maximum temperature is above $35^{\circ} \mathrm{C}$ and humidity is above $90 \%$. Therefore, the concentration of formaldehyde in summer and autumn was higher, and it was lower in winter and spring, which was consistent with the results of Figures 2, 3 and 4. Some studies have also shown that indoor formaldehyde concentration was higher in summer, while it was lower in winter [38, 39]. We can reduce formaldehyde concentration by reducing indoor temperature and humidity to reduce the damage to the human body $[41,42]$.

\section{Conclusions}

The purpose of this paper was to study the characteristics, monthly and seasonal variation rule of formaldehyde in the teaching machine room. The results indicated that the concentration of formaldehyde in the sitting breathing area and standing breathing area was small difference, which was higher in summer and autumn, while it was lower in winter and spring. The daily variation of formaldehyde concentration was not much different, while the monthly variation was quite different.

During the monitoring period, the formaldehyde concentration in the sitting breathing area and standing breathing area in the teaching machine room reached a maximum of $0.442 \mathrm{mg} / \mathrm{m}^{3}, 0.445 \mathrm{mg} / \mathrm{m}^{3}$ and $0.184 \mathrm{mg} / \mathrm{m}^{3}$, $0.213 \mathrm{mg} / \mathrm{m}^{3}$ in every summer(2016.7, 2017.6), respectively. After as long as eleven years, the concentration of formaldehyde in the teaching machine room was still seriously excessive.

The temperature and humidity were the main factors that affected the release of formaldehyde in the teaching machine room of Guangxi Normal University. The correlation $\quad\left(\mathrm{R}^{2}>0.87, \quad \mathrm{R}^{2}>0.85, \quad \mathrm{R}^{2}>0.81, \quad \mathrm{p}<0.01\right)$ between formaldehyde concentration and temperature, relative humidity or absolute humidity were strongly. As the temperature and humidity increase, the indoor formaldehyde concentration gradually increases. We can reduce the indoor formaldehyde concentration by reduce the temperature and humidity, thus reducing the harm to human body.

\section{Acknowledgments}

This study was supported by the National Science Foundation,
China (No.21467002), Key Laboratory of Ecology of Rare and Endangered Species and Environmental Protection (Guangxi Normal University), Ministry of Education, China, (No. ERESEP2015Z16), Key Laboratory of Karst Ecology and Environment Change (Guangxi Normal University), Guangxi Department of Education, China, (YRHJ16Z000), and the Fund of the 2012 Annual Major Scientific Projects of Guangxi Higher School (No.201201ZD006), Innovation Project of Guangxi Graduate Education(YCSW2019080), Innovation Project of Guangxi Graduate Education(YCSW2017064).

\section{References}

1. L. Zhang, J. Gao. Exploring the effects of international tourism on China's economic growth, energy consumption and environmental pollution: Evidence from a regional panel analysis, Renewable \& Sustainable Energy Reviews, 53 225-234 (2016).

2. P. Guo, K. Yokoyama, F. Y. Piao, K. S. Sakai, M. Khalequzzaman, M. Kamijima, T. Nakajima, F. Kitamura. Sick Building Syndrome by Indoor Air Pollution in Dalian, China, Int. J. Environ. Res. Public Health, 10 1489-1504 (2013).

3. G. Poulhet, S. Dusanter, S. Crunaire, N. Locoge, V. Gaudian, C. Merlen, P. Kaluzny, P. Coddeville. Investigation of formaldehyde sources in French schools using a passive flux sampler, Building and Environment, 71 111-120 (2014).

4. C. J. Jiang, S. S. Li, P. Y. Zhang, J. Wang. Pollution level and seasonal variations of carbonyl compounds, aromatic hydrocarbons and TVOC in a furniture mall in Beijing, China, Building and Environment, 69 227-232 (2013).

5. H. Reingruber, L. B. Pontel. Formaldehyde metabolism and its impact on human health, Current Opinion in Toxicology, 9 28-34 (2018).

6. D. Norback, J. H. Hashim, Z. Hashim, F. Ali. Volatile organic compounds (VOC), formaldehyde and nitrogen dioxide $\left(\mathrm{NO}_{2}\right)$ in schools in Johor Bahru, Malaysia: Associations with rhinitis, ocular, throat and dermal symptoms, headache and fatigue, Science of Total Environment, 592 153-160 (2017).

7. H. Chen, W. Liu, J. Cai, X. Y. Wang; Z. J. Zou, C. J. Sun. Household formaldehyde exposure and its associations with dwelling characteristics, lifestyle behaviours, and childhood health outcomes in Shanghai, China, Building and Environment, 125 143-152 (2017).

8. S. H. Hwang, J. Roh, W. M. Park. Evaluation of PM10, $\mathrm{CO}_{2}$, airborne bacteria, TVOCs, and formaldehyde in facilities for susceptible populations in South Korea, Environmental Pollution, 242 700-708 (2018).

9. J. K. Kim, H. J. Kim, D. H. Lim, Y. K. Lee, J. H. Kim. Effects of Indoor Air Pollutants on Atopic Dermatitis, Int. J. Environ, Res. Public Health, 13 1220-1233 (2016).

10. W. H Liang, X. D. Yang. Indoor formaldehyde in real buildings: Emission source identification, overall emission rate estimation, concentration 
increase and decay patterns, Building and Environment, 69 114-120 (2013).

11. F. Villanueva, A. Tapia, S. Lara, M. Amo-Salas. Indoor and outdoor air concentrations of volatile organic compounds and NO2 in schools of urban, industrial and rural areas in Central-Southern Spain, Science of the Total Environment, 622-623 222-235 (2018).

12. M. Jovanović, B. Vučićević, V. Turanjanin, M. Zivkovic, V. Spasojevic. Investigation of indoor and outdoor air quality of the classrooms at a school in Serbia, Energy, 77 42-48 (2014).

13. L. H. Huang, H. Qian, S. X. Deng, J. F. Guo, Y. P. Li, W. P. Zhao, Y. Yue. Urban residential indoor volatile organic compounds in summer, Beijing: Profile, concentration and source characterization, Atmospheric Environment, 188 1-11 (2018).

14. H. Tao, Y. S. Fan, X. Q. Li, Z. R. Zhang, W. S. Hou. Investigation of formaldehyde and TVOC in underground malls in Xi'an, China: Concentrations, sources, and affecting factors, Building and Environment, 85 85-93 (2015).

15. Y. Z Shang, B. Z. Li, A.N. Baldwin, Y. Ding, W. Yu, L. Cheng. Investigation of indoor air quality in shopping malls during summer in Western China using subjective survey and field measurement, Building and Environment, 108 1-11 (2016).

16. Y. Y. Chen, F. C. Sung, M. L. Chen, I. F. Mao, C. Y. Lu. Indoor Air Quality in the Metro System in North Taiwan, Int. J. Environ, Res. Public Health, 13 1200-1210 (2016).

17. B. Z. Li, Z. Cheng, R. M. Yao, H. Wang, W. Yu, Z. M. Bu, J. Xiong, T. J. W. Zhang, E. Essah, Z. W. Luo, M. Shahrestani, H. Kipen. An investigation of formaldehyde concentration in residences and the development of a model for the prediction of its emission rates, Building and Environment, 147 540-550 (2019).

18. X. G. Yin. Pollution pattern of formaldehyde and TVOC in indoor air and its control measures, Nature Environment \& Pollution Technology, 16 579-585 (2017).

19. G. Min, X. Q. Pei, F. F. Mo, J. L. Liu, X. Y. Shen. Formaldehyde concentration and its influencing factors in residential homes after decoration at Hangzhou, China, Journal of Environmental Sciences, 25 908-915 (2013).

20. M. Kozicki, M. Piasecki, A. Goljian, H. Deptula, Adam Nieslochowski. Emission of Volatile Organic Compounds (VOCs) from Dispersion and Cementitious Waterproofing Products, Sustainability, 10 2178-2194(2018).

21. L. Y. Liu, X. P. Yu, X. K. Dong, Q. Wang, Y. C. Wang, J. J. Huang. The Research on Formaldehyde Concentration Distribution in New Decorated Residential Buildings, Procedia Engineering, 205 1535-1541 (2017).

22. T. Iwata, H. Tsukahara, M. Hori. Aldehydes and
VOCs in newly-built unoccupied houses in Tokyo, Proceedings: Healthy Buildings, 154-159 (2003).

23. X. L. Dai, J. J. Liu, Y. H. Yin, X. Song, S. S. Jie. Modeling and controlling indoor formaldehyde concentrations in apartments: On-site investigation in all climate zones of China, Building and Environment, 127 98-106 (2018).

24. P. S. Juliana, P. T. B. S. Brano, M. C.M. Alvim-Ferraz, F. G. Martins, S. I. V. Sousa. Evaluation of Low-Cost Mitigation Measures Implemented to Improve Air Quality in Nursery and Primary Schools, Int. J. Environ. Res. Public Health, 14 585-606 (2017).

25. W. H. Liang, S. Yang, X. D. Yang. Long-Term Formaldehyde Emissions from Medium-Density Fiberboard in a Full-Scale Experimental Room: Emission Characteristics and the Effects of Temperature and Humidity, Environmental Science and Technology, 49 10349-10356 (2015).

26. W. H. Liang, M. Q. Lv, X. D. Yang. The effect of humidity on formaldehyde emission parameters of a medium-density fiberboard: Experimental observations and correlations, Building and Environment, 101 110-115 (2016).

27. A. Blondel, H. Plaisance. Screening of formaldehyde indoor sources and quantification of their emission using a passive sampler, Building and Environment, 46 1284-1291 (2011).

28. J. S. Pierce, A. Abelmana, J. T. Lotter, P. S. Ruestw, K. M. Unice, E. M. Beckett, H. A. Fritz, J. L. Bare, B. L. Finiey. An assessment of formaldehyde emissions from laminate flooring manufactured in China, Regulatory Toxicology and Pharmacology, 81 20-32 (2016).

29. J. Gunschera, S. Mentese, T. Salthammer, J. R. Andersen. Impact of building materials on indoor formaldehyde levels: Effect of ceiling tiles, mineral fiber insulation and gypsum board, Building and Environment, 64 138-145 (2013).

30. M. Cipolla, A. Izzotti, F. A nsaldi, P. Durando. Volatile Organic Compounds in Anatomical Pathology Wards: Comparative and Qualitative Assessment of Indoor Airborne Pollution, Int. J. Environ. Res. Public Health, 14 609-617 (2017).

31. Y. X. Sun, R. S. Cheng, J. Hou, Y. R. Song, S. G. Luo. Investigation on Indoor Air Quality in Tianjin Residential Buildings, Procedia Engineering, 205 3811-3815 (2017).

32. M. Derbez, B. Berthineau, V. Cochet, M. Lethrosne, C. Pignon, J. Riberron, S. Kirchner. Indoor air quality and comfort in seven newly built, energy-efficient houses in France, Building and Environment, 72 173-187 (2014).

33. HJ/T167-2004. Indoor Ambient air quality monitory technical specification of the People's Republic of China.

34. GB/T18204.26-2000. Methods for determination of formaldehyde in air of public places. 
35. W. Hong, M. W. Meng, J. L. Xie, D. D. Gao, Y. B. Zeng, H. Ai, C. Q. Chen, S. Y. Huang, Z. M. Zhou. Investigation of the Pollution Level and Affecting Factors of Formaldehyde in typical Public Places in Guangxi, China, Aerosol and Air Quality Research, 17 2816-2828 (2017).

36. GB/T1883-2002. Indoor air quality standard of the People's Republic of China.

37. M.J. Mendell. Indoor residential chemical emissions as risk factors for respiratory and allergic effects in children: a review, Indoor Air, 17 259-277 (2007).

38. S. J. Guo, M. Chen, X. L. He, W. W. Yang, J. H. Tan. Seasonal and diurnal characteristics of carbonyls in urban air in Qinzhou, China, Aerosol Air Qual. Res, 14 1653-1664 (2014).

39. S. D. Lu, H. Y. Zhu, L. H. Lu. Impact of green shading to building thermal environment in hot summer and warm winter area, Build Energy Effic, 44 40-47 (2016).

40. W. H. Liang, M. Q. Lv, X. D. Yang. The effect of humidity on formaldehyde emission parameters of a medium-density fiberboard: Experimental observations and correlations, Build. Environ, 101 110-115 (2016).

41. N. L. Gilbert, M. Guay, D. Gauvin, R. N. Dietz, C. C. Chen, B. Levesque. Air change rate and concentration of formaldehyde in residential indoor air, Atmospheric Environment, 42 2424-2428 (2008).

42. C. J. Jiang, D. D. Li, P. Y. Zhang, J. G. Li, J. Wang. Formaldehyde and volatile organic compound (VOC) emissions from particleboard: Identification of odorous compounds and effects of heat treatment, Building and Environment, 117 118-126 (2017). 